\title{
Efficacy and safety of prostaglandin analogues in patients with predominantly primary open-angle glaucoma or ocular hypertension: a meta-analysis
}

This article was published in the following Dove Press journal:

Clinical Ophthalmology

30 July 2009

Number of times this article has been viewed

\section{Oghenowede Eyawo' \\ Jean Nachega ${ }^{2,3}$ \\ Pierre Lefebvre ${ }^{4}$ \\ David Meyer ${ }^{5}$ \\ Beth Rachlis ${ }^{6}$ \\ Chia-Wen Lee ${ }^{7}$ \\ Steven Kelly \\ Edward Mills ${ }^{8}$}

'Faculty of Health Sciences, Simon Fraser University, Vancouver, Canada; ${ }^{2}$ Division of Clinical Pharmacology and Medicine, University of Cape Town, Cape Town, South Africa; ${ }^{3}$ Johns Hopkins Bloomberg School of Public Health, Baltimore, USA; ${ }^{4}$ Department of Ophthalmology, Moorfields Eye Hospital, London, United Kingdom; ${ }^{5}$ Department of Ophthalmology, Stellenbosch University, Cape Town, South Africa; ${ }^{6}$ Department of Public Health, University of Toronto, Toronto, Canada; ${ }^{7}$ Outcome Research and Evidence Based Medicine, Pfizer Ltd UK. Tadworth, UK; ${ }^{8}$ Department of Clinical Epidemiology and Biostatistics, McMaster University, Hamilton, Canada
Correspondence: Edward Mills 3I I-674 Leg in Boot Square,Vancouver, BC,V5Z4B4, Canada

Email emills@cfenet.ubc.ca
Background: First-line therapy for primary open-angle glaucoma and ocular hypertension generally involves prostaglandin analogue therapy. The relative efficacy of differing prostaglandin therapy is disputed.

Methods: A meta-analysis was conducted of head-to-head randomized trials of prostaglandin therapies. We included randomized trials assessing head-to-head evaluations of prostaglandin analogues travoprost, latanoprost and bimatoprost in patients with predominantly primary open-angle glaucoma or ocular hypertension. Findings were interpreted in light of equivalence margins.

Results: Our search identified 16 eligible trials, of which 15 were included in the meta-analysis Trials were, in general, poorly reported. We pooled 9 trials assessing IOP-lowering effects of travoprost vs latanoprost (total $\mathrm{n}=1098$, weighted mean difference [WMD], $-0.24 \mathrm{mmHg}$, $95 \% \mathrm{CI},-0.87$ to $0.38, P=0.45, \mathrm{I}^{2}=56 \%, 95 \% \mathrm{CI}, 0$ to 0.77 , heterogeneity $P=0.01$ ). Eight trials assessed travoprost vs bimatoprost (total $\mathrm{n}=714$, WMD, $0.88 \mathrm{mmHg}, 95 \% \mathrm{CI}, 0.13$ to 1.63, $P=0.02, \mathrm{I}^{2}=56 \%, 95 \% \mathrm{CI}, 0 \%$ to $78 \%$, heterogeneity $P=0.02$ ). And 8 trials assessed latanoprost vs bimatoprost (total $\mathrm{n}=943$, WMD, $0.73 \mathrm{mmHg}, 95 \% \mathrm{CI}, 0.10$ to $1.37, P=0.02$, $\mathrm{I}^{2}=47 \%, 95 \% \mathrm{CI}, 0 \%$ to $74 \%$, heterogeneity $\left.P=0.06\right)$. Travoprost was associated with greater incidence of conjunctival hyperemia than latanoprost (RR 5.71, 95\% CI, 1.81 to 18.02 , $P \leq 0.001, \mathrm{I}^{2}=97 \%, 95 \% \mathrm{CI}, 95$ to $\left.98, P \leq 0.001\right)$. Five trials assessing latanoprost and bimatoprost revealed an elevated risk of conjunctival hyperemia with bimatoprost (RR 1.59, 95\% CI, 1.02 to $2.48, P=0.04, \mathrm{I}^{2}=76 \%, 95 \% \mathrm{CI}, 16$ to $88, P=0.002$ ).

Conclusion: Randomized head-to-head evaluations of prostaglandin therapy demonstrate similar efficacy effects, but differing hyperemia effects.

Keywords: prostaglandin analogues, primary open-angle glaucoma, ocular hypertension, travoprost, latanoprost, bimatoprost

\section{Background}

Primary open-angle glaucoma $(\mathrm{POAG})$ is a progressive optic neuropathy characterized by acquired loss of retinal ganglion cells and atrophy of the optic nerve and is a leading cause of blindness in both the developed and developing world. ${ }^{1}$ Elevated intraocular pressure (IOP) has been identified as a major risk factor for primary open-angle glaucoma and thus drugs that reduce IOP have the potential to prevent or delay optic nerve damage and prolong vision. ${ }^{2,3}$ The Ocular Hypertension Treatment Study, a large randomized trial of 1636 participants with elevated IOP, that compared topical medication use with only observation found important decreases in IOP (mean decrease in active group of $22.5 \%$, standard deviation [SD] $9.9 \%$, compared 
to a mean decrease of $4.0 \%$ in the observation group, SD $11.6 \%$ ) with topical medication use and a large decrease in progression to POAG (hazard ratio, 0.40 , 95\% confidence interval [CI] $0.27-0.59, \mathrm{P} \leq 0.0001)$ over 5 years. The extent to which individual topical agents exerted differing therapeutic effects in the trial is, however, unknown., ${ }^{4,5}$ Of all current therapies utilized in the treatment of POAG associated with raised IOP, prostaglandin analogues (PGAs) demonstrate consistent superiority over beta-adrenergic blockers (eg, betaxolol), alpha-adrenergic agonists (eg, brimonidine) or a topical carbonic anhydrase inhibitor (dorzolamide) therapies as far as IOP-lowering efficacy is concerned. ${ }^{6-8}$ More invasive treatment strategies, such as surgery, may be effective, but also can result in severe adverse events and population-heavy costs. ${ }^{9,10}$ Prostaglandin analogues lower IOP by increasing the uveoscleral outflow of aqueous humor. ${ }^{7}$ They are effective in reducing IOP and have the additional advantage of requiring only once a day administration. ${ }^{11}$

Current prostaglandin therapies available in the United States and United Kingdom include bimatoprost (0.03\%), latanoprost $(0.005 \%)$, and travoprost $(0.004 \%)$. Although there is extensive evidence on the efficacy of the individual prostaglandin drugs, data determining the comparative effectiveness of the three drugs are sparse. ${ }^{11}$

We aimed to undertake a rigorous systematic review of the literature to identify randomized trials evaluating the head-to-head effectiveness of PGAs in the treatment of POAG and ocular hypertension and to conduct a meta-analysis of their results to improve understanding of the drugs' relative efficacy.

\section{Methods}

\section{Eligibility criteria}

We included any randomized trial that evaluated bimatoprost $(0.03 \%)$, latanoprost $(0.005 \%)$, or travoprost $(0.004 \%)$. We included randomized trials of at least 3 months' duration. Studies had to compare a prostaglandin, for the purpose of affecting any of the following clinically important glaucoma and ocular hypertension outcomes: IOP; response rates; and adverse events. With the presence of head-to-head evaluations, we excluded studies comparing prostaglandins to other glaucoma treatments, dose-finding studies, cross-over trials, and short-term evaluations.

\section{Search strategy}

We established a search strategy based on the Medical Subject Headings [MeSH] and clinical outcomes.
We searched independently the following databases (from inception to May 2008): MEDLINE, EMBASE, and Cochrane CENTRAL. We additionally searched conference abstracts via Greynet.org. Finally, we searched Web of Science, a database that included the full text of journals (OVID, Science Direct, and Ingenta, including articles in full text from approximately 1700 journals since 1993). In addition, we searched the bibliographies of published systematic reviews ${ }^{6,8,10-14}$ and American Academy of Ophthalmology guidelines. ${ }^{15}$ We also contacted the authors of trials for study clarifications, where required. Searches were not limited by language, sex, or age.

\section{Study selection}

Three investigators (OE, EM, BR), working independently, scanned all abstracts, and obtained the full-text reports of records, which indicated or suggested that the study was a randomized trial evaluating PGA therapy in a head-to-head design. After obtaining full reports of the candidate trials (either in a full peer-reviewed publication or press article) the same reviewers independently assessed eligibility from full-text papers.

\section{Data collection}

The same reviewers conducted data extraction independently using a standardized pre-piloted form. Reviewers collected information about the PGAs, the population studied (age, sex, underlying conditions), and the treatment effect on specified outcomes: IOP changes, response rates, adverse events, and the length of follow-up. Study evaluation included general methodological quality features assessing methods of randomization, allocation concealment, use of intention-to-treat analysis, and methods of blinding. ${ }^{16,17}$ Because most head-tohead trials are designed to demonstrate equivalence, ${ }^{18}$ we also noted whether the authors had denoted an a priori margin of equivalence $(\rho) \cdot{ }^{19,20}$ We entered the data into an electronic database such that triplicate entries existed for each study; when the entries did not match, we resolved differences through discussion and consensus.

\section{Data analysis}

In order to assess inter-rater reliability on inclusion of articles, we calculated the $P h i$ statistic, which provides a measure of inter-observer agreement independent of chance. ${ }^{21}$ For the primary outcome of IOP-lowering effects between groups at study completion, we calculated the weighted mean difference (WMD) across studies using the DerSimonian-Laird random effects model, that recognizes 
and anchors studies as a sample of all potential studies, and incorporates an additional between-study component to the estimate of variability. ${ }^{22}$ Pooled differences over all time points were generally reported, but when absent we contacted the study authors and, if no response, assumed the time point closest to 8 am as the primary time point. When authors reported standard deviations, we used them directly. When standard deviations were unavailable, we computed them from the standard errors or the test statistics if exact p-values were provided.

For response rates and adverse events of hyperemia, we calculated the relative risk [RR] and appropriate 95\% CIs of outcomes according to the number of events reported in the original studies. In the event of zero outcome events in one arm of a trial, we used the Haldane method and added 0.5 to each arm. ${ }^{23} \mathrm{We}$ calculated the $\mathrm{I}^{2}$ statistic for each analysis as a measure of the proportion of the overall variation that is attributable to between-study heterogeneity, with appropriate $95 \%$ CIs. To investigate the association between study duration and IOP-lowering effects, we conducted a weighted meta-regression for study characteristics using the unrestricted maximum likelihood model. ${ }^{24}$ We chose this co-variate as we believed it is likely to influence trial outcomes beyond chance. Forest plots are displayed for each
PGA analysis, showing individual study WMD with 95\% CIs, and the overall DerSimmonian-Laird pooled estimate. We considered equivalence if both upper and lower 95\% CIs for the pooled analysis were within $1.5 \mathrm{mmHg}$ of zero difference, as is a commonly used margin of equivalence. ${ }^{25}$ Analyses were conducted using STATA (version 9, www. stata.com) and StatsDirect (v.2.6.5, www.statsdirect.com, Manchester).

\section{Results}

Our initial database searches identified a total of 1144 abstracts. After a thorough assessment, 215 abstracts were excluded since they were review articles. Another 549 abstracts were excluded as they were not relevant to present study. Overall, 380 full-text papers were retrieved in full-text for possible inclusion. Upon careful review of the 380 full-text articles, we included 15 full text articles and 1 conference abstract in our analysis. During the review process, we were able to add one study ${ }^{26}$ and removed another, ${ }^{27}$ that was an early report of the later publication. Figure 1 presents details of the exclusion criteria at the various stages during the study selection process. Five trials had more than 2 intervention arms, ${ }^{28-32}$ hence 9 trials assessed travoprost versus latanoprost, ${ }^{28-36} 8$ examined travoprost

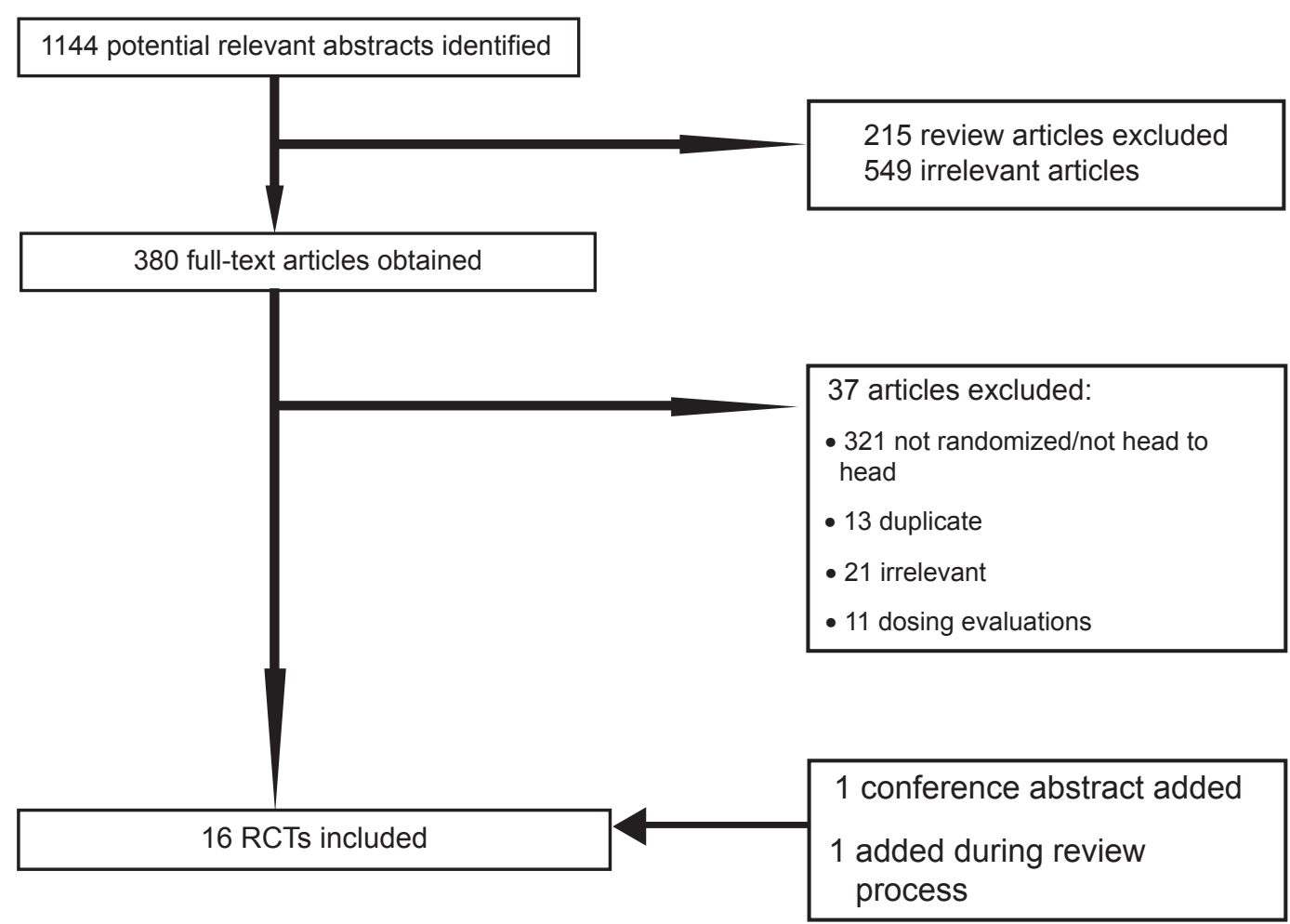

Figure I Flow diagram of included studies. 
versus bimatoprost, ${ }^{26,28-32,37,38}$ and 8 of latanoprost versus bimatoprost. ${ }^{28-32,39-41}$ We did not pool the data from one trial, reported as an abstract, as we were unable to determine the group sizes. ${ }^{42}$ Table 1 and 2 report the study characteristics and quality (see Tables 1 and 2). As demonstrated in Table 2, studies were of moderate to low quality.

\section{Primary outcomes, IOP-lowering effects}

Table 3 presents IOP-lowering effects at the study conclusion for all included trials. We pooled 9 trials assessing travoprost to latanoprost (total $n=1098$, Figure 2). The weighted mean difference across groups is $-0.24 \mathrm{mmHg}(95 \% \mathrm{CI},-0.87$ to $0.38, P=0.45, \mathrm{I}^{2}=56 \%, 95 \% \mathrm{CI}, 0$ to 0.77 , heterogeneity $P=0.01)$. When we pooled 8 trials assessing travoprost to bimatoprost (total $n=688$, Figure 3 ), we found a pooled weighted mean difference of $0.88 \mathrm{mmHg}, 95 \% \mathrm{CI}, 0.13$ to $1.63, P=0.02, \mathrm{I}^{2}=56 \%, 95 \% \mathrm{CI}, 0$ to 78 ). Finally, we pooled 8 trials assessing latanoprost with bimatoprost (total $\mathrm{n}=974$, Figure 4), we found a pooled weighted mean difference of $0.73 \mathrm{mmHg}$ (95\% CI, 0.10 to $1.37, P=0.02, \mathrm{I}^{2}=47 \%, 95 \%$ CI, 0 to 74 , heterogeneity $P=0.06$ ). Study duration was not associated with therapeutic effects (B coefficient $-0.21,95 \%$ CI, -0.33 to 1.09 ).

\section{Response rates}

Response rates were defined in 8 trials, but were not defined uniformly across these trials (Table 4). Response rates were pooled across studies when the definition was deemed similar enough. Two trials comparing travoprost to latanoprost provided a pooled RR of 1.15 (95\% CI, 0.99 to $1.33, P=0.07)$. Three trials comparing travoprost to bimatoprost had a pooled RR of 0.82 (95\% CI, 0.71 to $0.95, P=0.009, \mathrm{I}^{2}=0 \%, 95 \% \mathrm{CI}, 0$ to $\left.72, P=0.88\right)$. Three trials comparing latanoprost to bimatoprost provided a pooled RR of 0.98 (95\% CI, 0.76-1.26, $P=0.87, \mathrm{I}^{2}=78$, 95\% CI, 0 to $91, P=0.01)$.

\section{Conjunctival hyperemia}

Six trials reporting hyperemia outcomes for travoprost and latanoprost were pooled. Travoprost was associated with conjunctival hyperemia significantly more than latanoprost (RR 5.71, 95\% CI, 1.81 to $18.02, P \leq 0.001$, $\mathrm{I}^{2}=97 \%, 95 \% \mathrm{CI}, 95$ to $\left.98, P \leq 0.001\right)$. In a single trial of travoprost and bimatoprost, there was a decreased risk of conjunctival hyperemia with bimatoprost (RR 0.82 , 95\% CI, 0.69 to $0.97, P=0.02$ ). Finally, pooling five trials assessing latanoprost and bimatoprost revealed an

Table I Characteristics of included studies

\begin{tabular}{|c|c|c|c|c|c|c|c|c|c|c|c|c|}
\hline \multirow[t]{2}{*}{ Author, year } & \multirow[t]{2}{*}{ TRAV n } & \multirow[t]{2}{*}{ LAT $n$} & \multirow{2}{*}{ BIM n } & \multirow{2}{*}{$\begin{array}{l}\text { Duration } \\
\text { (months) }\end{array}$} & \multirow{2}{*}{ Mean age } & \multirow[t]{2}{*}{$\operatorname{Sex}(M / F)$} & \multicolumn{3}{|c|}{ Types of glaucoma } & \multirow[t]{2}{*}{ TRAV dose } & \multirow[t]{2}{*}{ LAT dose } & \multirow[t]{2}{*}{ BIM dose } \\
\hline & & & & & & & POA & $\mathrm{OH}$ & Other & & & \\
\hline Arcieri $2005^{32}$ & 17 & 15 & 16 & 6 & 67 & $34 / 30$ & 34 & 0 & 30 & $0.004 \%$ & $0.005 \%$ & $0.03 \%$ \\
\hline Cantor $2006^{26}$ & 81 & & 76 & 6 & 65 & $81 / 76$ & 108 & 48 & 1 & $0.004 \%$ & & $0.03 \%$ \\
\hline Cardascia $2003^{34}$ & 9 & 9 & & 6 & 52 & $9 / 9$ & 18 & & & NA & NA & \\
\hline Cellini $2004^{30}$ & 20 & 20 & 20 & 6 & 64 & $32 / 28$ & 60 & & & $0.004 \%$ & $0.005 \%$ & $0.03 \%$ \\
\hline Dirks $2006^{39}$ & & 27 & 33 & 3 & 71 & $21 / 39$ & & & 60 & & $0.005 \%$ & $0.03 \%$ \\
\hline Gandolfi $200 \mathrm{I}^{40}$ & & 113 & 119 & 3 & 62 & $87 / 145$ & 132 & 81 & 13 & $0.004 \%$ & $0.005 \%$ & $0.03 \%$ \\
\hline Hepsen $2007^{29}$ & 15 & 15 & 15 & & 62 & $20 / 25$ & & 45 & & $0.004 \%$ & $0.005 \%$ & $0.03 \%$ \\
\hline Koz $2007^{28}$ & 20 & 20 & 20 & 6 & 53 & $35 / 25$ & 36 & 24 & & $0.004 \%$ & $0.005 \%$ & $0.03 \%$ \\
\hline \multicolumn{13}{|l|}{ Mundorf $2004^{42}$} \\
\hline & & & & 3 & & & & & & $0.004 \%$ & & $0.03 \%$ \\
\hline Netland $200 \mathrm{I}^{36}$ & 197 & 193 & & 12 & 64 & $392 / 395$ & 530 & 247 & 10 & $0.004 \%$ & $0.005 \%$ & \\
\hline Noecker $2003 \mathrm{a}^{41}$ & & 136 & 133 & 6 & 61 & $103 / 166$ & 150 & 93 & 26 & & $0.005 \%$ & $0.03 \%$ \\
\hline Noecker $2003 b^{38}$ & 15 & & 16 & 3 & 65 & $1 \mathrm{I} / 20$ & 28 & 3 & & $0.004 \%$ & & $0.03 \%$ \\
\hline Noecker $2006^{37}$ & 45 & & 49 & 3 & 63 & $37 / 57$ & 67 & 27 & & $0.004 \%$ & & $0.03 \%$ \\
\hline Parmaksiz $2006^{35}$ & 18 & 16 & & 6 & 67 & $25 / 25$ & & & 50 & $0.004 \%$ & $0.005 \%$ & \\
\hline Parrish $2003^{31}$ & 138 & 136 & 136 & 3 & 65 & $172 / 238$ & 309 & 95 & 6 & $0.004 \%$ & $0.005 \%$ & $0.03 \%$ \\
\hline Topouzis $2007^{33}$ & 168 & 72 & & 12 & 65 & $136 / 196$ & 233 & 64 & 36 & $0.004 \%$ & $0.005 \%$ & \\
\hline
\end{tabular}

Abbreviations: TRAV, travoprost; LAT, latanoprost; BIM, bimatoprost; M/F, male/female; NA, data not available; POAG, primary open-angle glaucoma; OH, ocular hypertension; Other, other types of chronic open angle glaucoma. 
Table 2 Methodological issues in included studies

\begin{tabular}{|c|c|c|c|c|c|}
\hline Author, year & Randomization & Allocation concealment & ITT & $\begin{array}{l}\text { Description of margin } \\
\text { of equivalence }\end{array}$ & Blinding status \\
\hline Netland $200 I^{36}$ & Yes & Yes & Yes & Yes & Yes \\
\hline Arcieri $2005^{32}$ & Yes & Yes & No & No & Yes \\
\hline Cantor $2006^{26}$ & Yes & Yes & Yes & Yes & Yes \\
\hline Cardascia $2003^{34}$ & No & No & No & No & Yes \\
\hline Noecker $2003 a^{41}$ & Yes & Yes & Yes & Yes & Yes \\
\hline Koz $2007^{28}$ & No & No & No & Yes & Yes \\
\hline Noecker $2003 b^{38}$ & Yes & Unclear & No & No & Yes \\
\hline Noecker $2006^{37}$ & Yes & No & Yes & No & Yes \\
\hline Dirks $2006^{39}$ & Yes & Unclear & No & No & Yes \\
\hline Gandolfi $200 I^{40}$ & Yes & Unclear & Yes & Yes & Yes \\
\hline Parrish $2003^{31}$ & Yes & Yes & Yes & Yes & Yes \\
\hline Cellini $2004^{30}$ & Yes & Unclear & No & No & Yes \\
\hline Parmaksiz $2006^{35}$ & Yes & Unclear & No & No & Yes \\
\hline Mundorf $2004^{42}$ & No & No & No & No & Yes \\
\hline Hepsen $2007^{29}$ & No & No & No & No & Yes \\
\hline Topouzis $2007^{33}$ & Yes & No & $\begin{array}{l}\text { Yes - for } \\
\text { safety analysis } \\
\text { only }\end{array}$ & Yes & Yes \\
\hline
\end{tabular}

Abbreviation: ITT, intention to treat.

elevated risk of conjunctival hyperemia with bimatoprost (RR 1.59, 95\% CI, 1.02-2.48, $P=0.04, \mathrm{I}^{2}=76 \%, 95 \%$ CI, 16 to $88, P=0.002$ ).

\section{Discussion}

As the third leading preventable cause of blindness, glaucoma affects approximately 105 million people worldwide. ${ }^{1}$ The findings of this analysis should therefore be of interest to patients, clinicians, policy makers and health insurance funders. We found that all three PGA drugs produce similar efficacy, as measured by response rate and IOP-lowering, across a diverse population of POAG and ocular hypertension patients. The practical clinical importance of this finding is important as clinicians consult with patients about optimal interventions and consider issues of safety, long-term efficacy and cost.

This analysis has several strengths and limitations. Strengths include the extensive searches and contact with authors of the primary trial reports, as well as searches and data abstraction by three independent reviewers. Our analysis is limited as there may still be unpublished trials. We believe it is possible, and perhaps even likely, that negative studies have remained unpublished. It is possible that contacting companies may have identified unpublished studies; however, in our experience, companies do not openly share unpublished data. Another limitation is that reporting of methodological criteria was very inconsistent and definitions were not uniform. For example, responder outcomes were often not reported; of 16 included trials, only 9 reported responders, but used 7 different criteria for evaluating response rates. We found moderate heterogeneity in several analyses and were unable to explain it using a priori explanations, thus our inferences on the completeness of these estimates are weakened.

Some may disagree with our inclusion of a trial evaluating timolol plus travoprost versus timolol alone. ${ }^{33}$ We believe that such an evaluation meets our inclusion criteria of a prostaglandin versus an inert control as the prostaglandin effect here is the same relative effect as if it were prostaglandin versus nothing. We have conducted a sensitivity analysis to examine if our findings would differ on the primary outcome of IOP-lowering effects. When we examined travoprost versus latanoprost, we found a weighed mean difference of $-0.17\left(95 \% \mathrm{CI},-0.90\right.$ to $\left.0.54, P=0.63, \mathrm{I}^{2}=61 \%\right) \mathrm{mmHg}$, indicating no difference.

Interpreting noninferiority and equivalence studies may be challenging for readers. Figure 5 displays the recommended interpretation of confidence intervals for equivalence. Only 7 trials reported their analysis as intent-to-treat. As these trials were continuous outcomes and reported their changes by group, we were unable to calculate the intent-to-treat outcomes 
Table 3 Mean intraocular pressure (SD) outcomes for included studies

\begin{tabular}{|c|c|c|c|}
\hline Author, year & Travoprost & Latanoprost & Bimatoprost \\
\hline Arcieri $2005^{32}$ & $14.20(1.80)$ & I 4.90 (I.70) & $14.30(2.20)$ \\
\hline Cantor $2006^{26}$ & $18.70(3.20)$ & & $17.50(3.30)$ \\
\hline Cardascia $2003^{34}$ & I6.I (I.9) & $16.5(1.7)$ & \\
\hline Cellini $2004^{30}$ & $17.30(2.3)$ & $18.10(2.3)$ & $17.70(3.8)$ \\
\hline Dirks $2006^{39}$ & & 13.50 (3.30) & I3.20 (3.30) \\
\hline Gandolfi $200 I^{40}$ & & I7.80 (3.04) & $17.50(3.04)$ \\
\hline Hepsen $2007^{29}$ & $16.30(3.2)$ & $16.10(3.2)$ & $15.60(3.2)$ \\
\hline Koz $2007^{28}$ & 20.9 (1.9) & $20.8(2.4)$ & I8.3 (I.2) \\
\hline Mundorf $2004^{42}$ & I8.50 (3.30) & & $16.80(3.30)$ \\
\hline Netland $200 \mathrm{I}^{36}$ & I $8.00(4.22)$ & $19.40(3.97)$ & \\
\hline Noecker $2003^{41}$ & & $18.20(7.00)$ & $16.8(6.9)$ \\
\hline Noecker $2003^{38}$ & $18.60(9.50)$ & & $17.10(9.50)$ \\
\hline Noecker $2006^{37}$ & $17.70(3.30)$ & & $17.10(3.30)$ \\
\hline Parmaksiz $2006^{35}$ & $16.00(2.80)$ & $14.30(1.90)$ & \\
\hline Parrish $2003^{31}$ & $17.60(3.70)$ & $17.10(3.10)$ & $17.00(3.30)$ \\
\hline Topouzis $2007^{33}$ & $17.10(3.80)$ & $17.70(3.90)$ & \\
\hline
\end{tabular}

for each trial. This issue is now receiving debate within the trial community and some argue that only studies reporting intent-to-treat be included. ${ }^{43}$ Without access to individual data, it is impossible to calculate intent-to-treat outcomes.

Our meta-analysis found equivalence across all three included drugs. Our findings stand in contrast to claims of superiority in the included studies. We are concerned with the general poor quality of included studies and the biased claims of superiority observed in the published reports. We found several instances where the primary outcomes were not significantly different, but the authors reported them as clinically important in their conclusions. ${ }^{33}$ Further, on average, the trials included in our analysis were small. There is a clear need for minimum sample sizes in equivalence trials of PGAs to avoid wasted resources and potentially spurious outcomes.

Initially, when the PGAs arrived on the market, beta-adrenergic blockers were widely considered first-line therapy in POAG and clinicians at that time decided to reserve the PGAs for cases where beta-blockers failed to reduce the IOP adequately. ${ }^{44}$ However over the past 10 years the PGAs have emerged as the most popular first-line IOP-lowering class of drugs in the developed world. ${ }^{45}$ This approach is widely supported by international glaucoma societies. Guidelines generally advocate that if the first-choice therapy is not measurably effective on IOP, it is then preferable to change the initial therapy rather than switch to a different class drug. The issue of cost, however, still compels developing countries to reserve this class of drug for post-primary therapy or add-on treatment. As this study confirms equivalence between the three brands of PGAs, policy makers, especially in developing countries, may base their selection of a particular drug for public health programs on other practical issues such as cost alone.

As noncompliance with therapy plays a large role in progression to blindness, confirmation that all three drugs

Effect size meta-analysis plot [random effects]

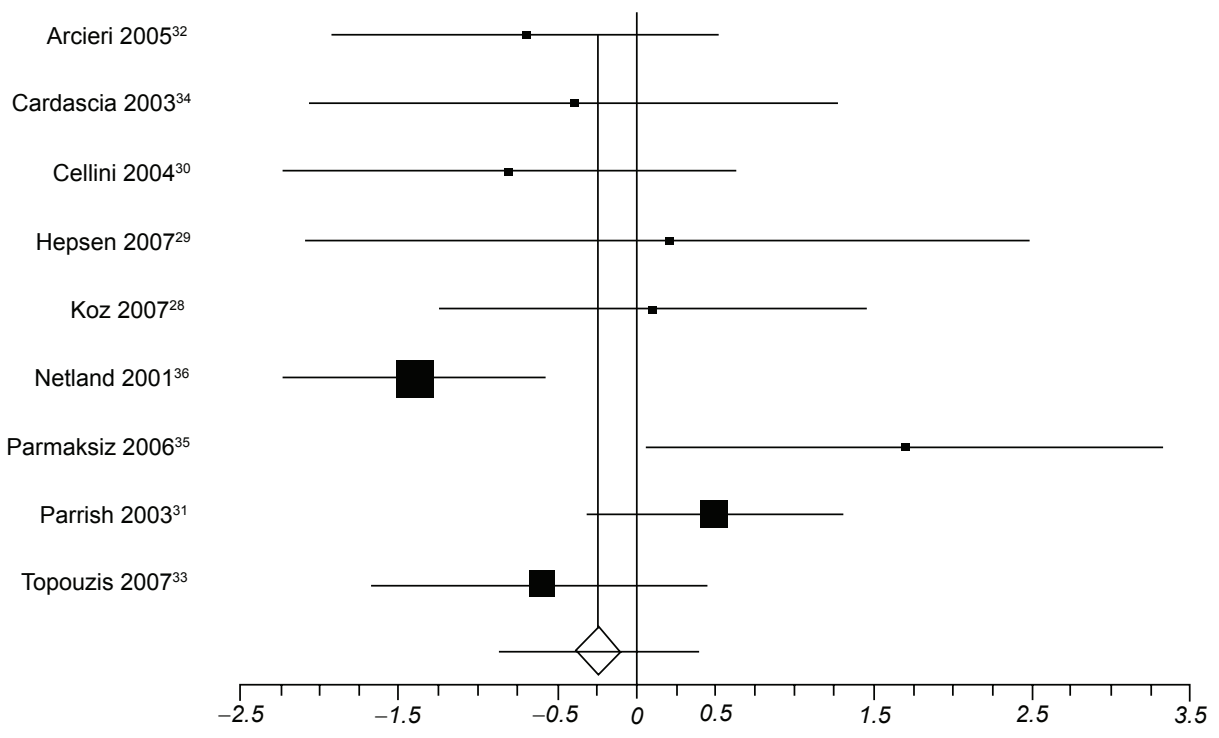

Figure 2 Meta-analysis, travoprost versus latanoprost for IOP-lowering effects. 
Effect size meta-analysis plot [random effects]

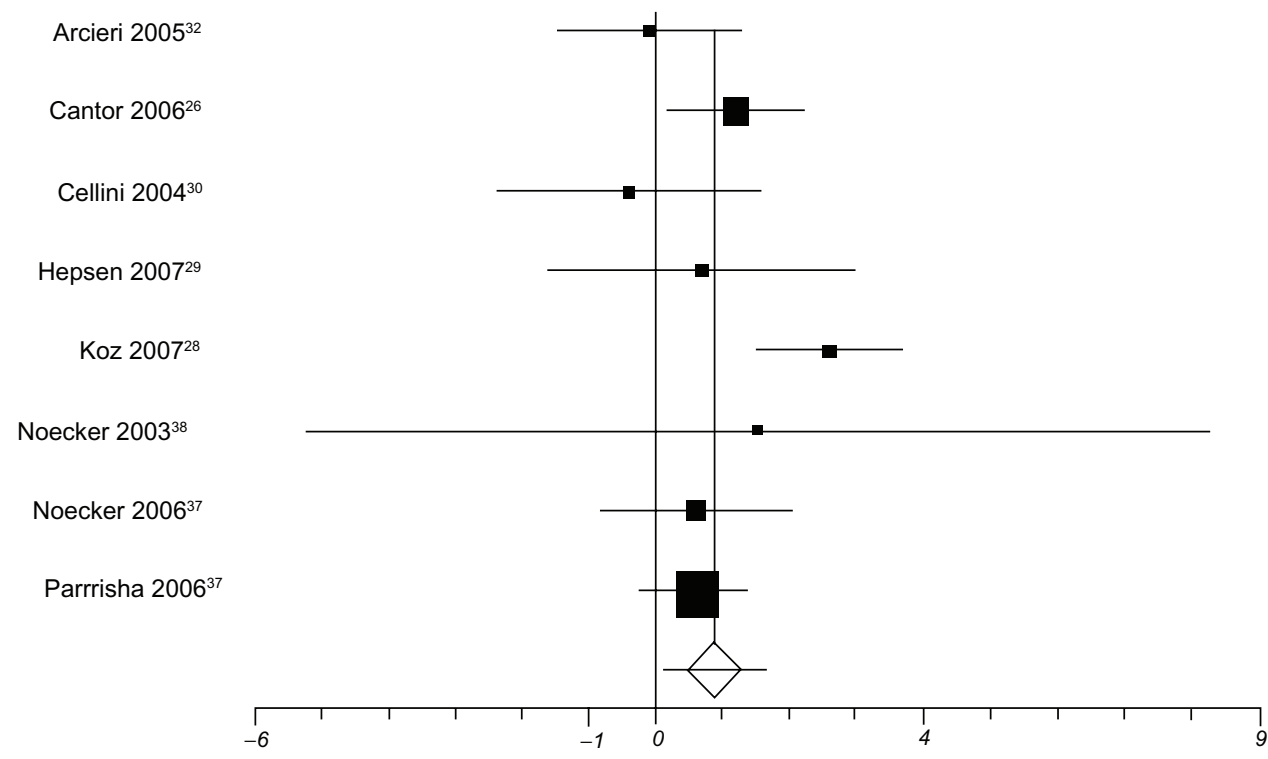

Figure 3 Meta-analysis, travoprost versus bimatoprost for IOP-lowering effects.

are equally effective is encouraging. The favorable dosing schedule (once a day), acceptable side-effect profile and IOP-lowering efficacy make the PGAs highly favored among ophthalmologists and patients alike. Because dosing schedule, cost and treatment side-effects all have to be taken into account when choosing a therapy, the comparative conjunctival hyperemia side-effect of this class is important. Side-effects of the three different drugs are generally identical except for conjunctival hyperemia.

We found increased rates of conjunctival hyperemia associated with especially travoprost but also with bimatoprost as compared to latanoprost. Conjunctival

Table 4 Definition and outcomes among 'Responders' in included studies

\begin{tabular}{|c|c|c|c|c|c|c|}
\hline Author, year & Definition of response & Travoprost & Latanoprost & Bimatoprost & $\mathbf{R R}$ & $95 \% \mathrm{Cl}$ \\
\hline Arcieri $2005^{32}$ & No measure & & & & & \\
\hline Cantor $2006^{26}$ & Reaching IOP of $\geq 20 \mathrm{mmHg}$ & $52 / 81$ & & $59 / 76$ & 0.83 & $0.68-1.01$ \\
\hline Cardascia $2003^{34}$ & No measure & & & & & \\
\hline Cellini $2004^{30}$ & No measure & & & & & \\
\hline Dirks $2006^{39}$ & $\begin{array}{l}\text { If current regimen should } \\
\text { continue }\end{array}$ & & $17 / 20$ & $24 / 29$ & 0.97 & $0.76-1.25$ \\
\hline Gandolfi $200 I^{40}$ & Reaching IOP of $\leq 17 \mathrm{mmHg}$ & & $63 / 119$ & $50 / 113$ & 0.84 & $0.64-1.09$ \\
\hline Hepsen $2007^{29}$ & No measure & & & & & \\
\hline Koz $2007^{28}$ & No measure & & & & & \\
\hline Mundorf $2004^{42}$ & No measure & & & & & \\
\hline Netland $2001^{36}$ & Reaching IOP of $\leq 17 \mathrm{mmHg}$ & $108 / 197$ & $97 / 193$ & & 1.09 & $0.90-1.32$ \\
\hline Noecker $2003^{41}$ & At least $15 \%$ IOP decrease & & $98 / 136$ & $118 / 133$ & 1.23 & $1.09-1.39$ \\
\hline Noecker $2003^{38}$ & Reaching IOP $\leq 17 \mathrm{mmHg}$ & $8 / 15$ & & $9 / 16$ & 0.95 & $0.50-1.80$ \\
\hline Noecker $2006^{35}$ & At least $20 \%$ IOP decrease & $31 / 45$ & & $42 / 49$ & 0.80 & $0.64-1.01$ \\
\hline Parmaksiz $2006^{35}$ & No measure & & & & & \\
\hline Parrish $2003^{31}$ & No measure & & & & & \\
\hline Topouzis $2007^{33}$ & Reaching $I O P \leq 18 \mathrm{mmHg}$ & $86 / 168$ & $68 / 164$ & & 0.91 & $0.7 I-1.16$ \\
\hline
\end{tabular}

Abbreviations: $\mathrm{Cl}$, confidence interval; IOP, intraocular pressure; $\mathrm{RR}$, relative risk. 
Effect size meta-analysis plot [random effects]

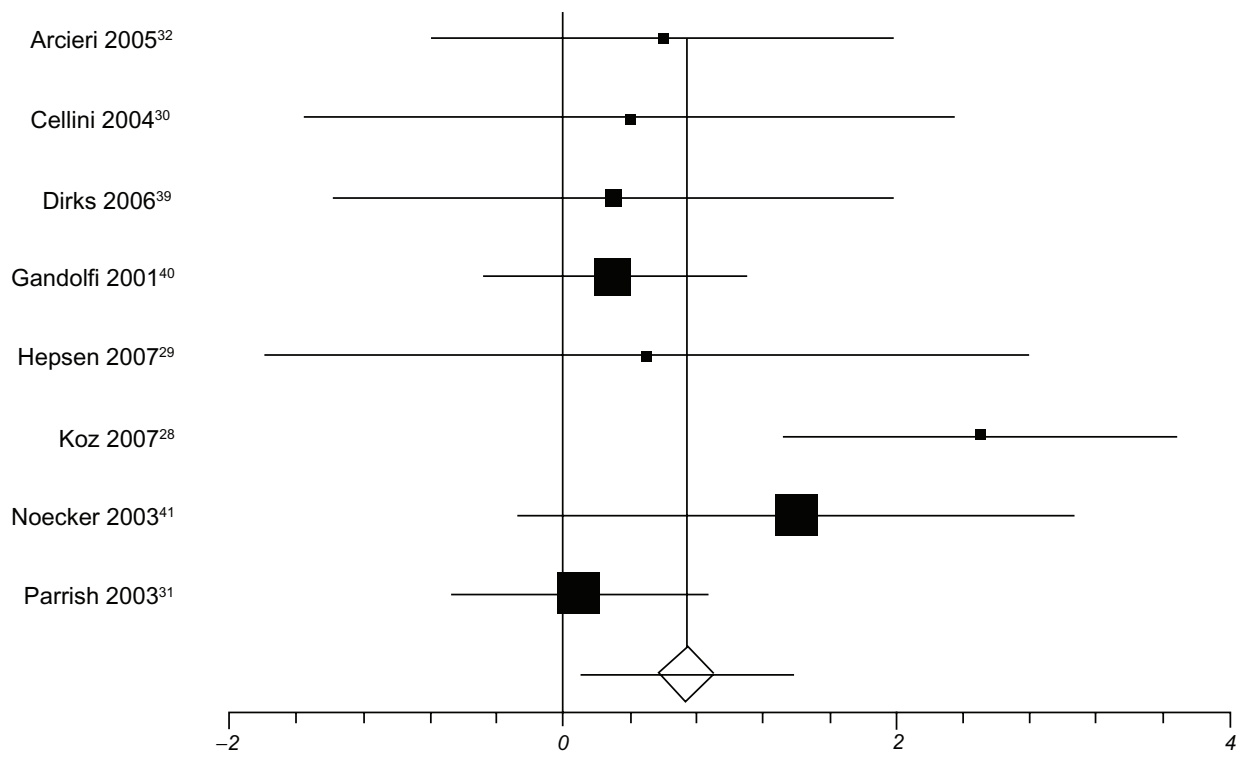

Figure 4 Meta-analysis of latanoprost versus bimatoprost for IOP-lowering effects.

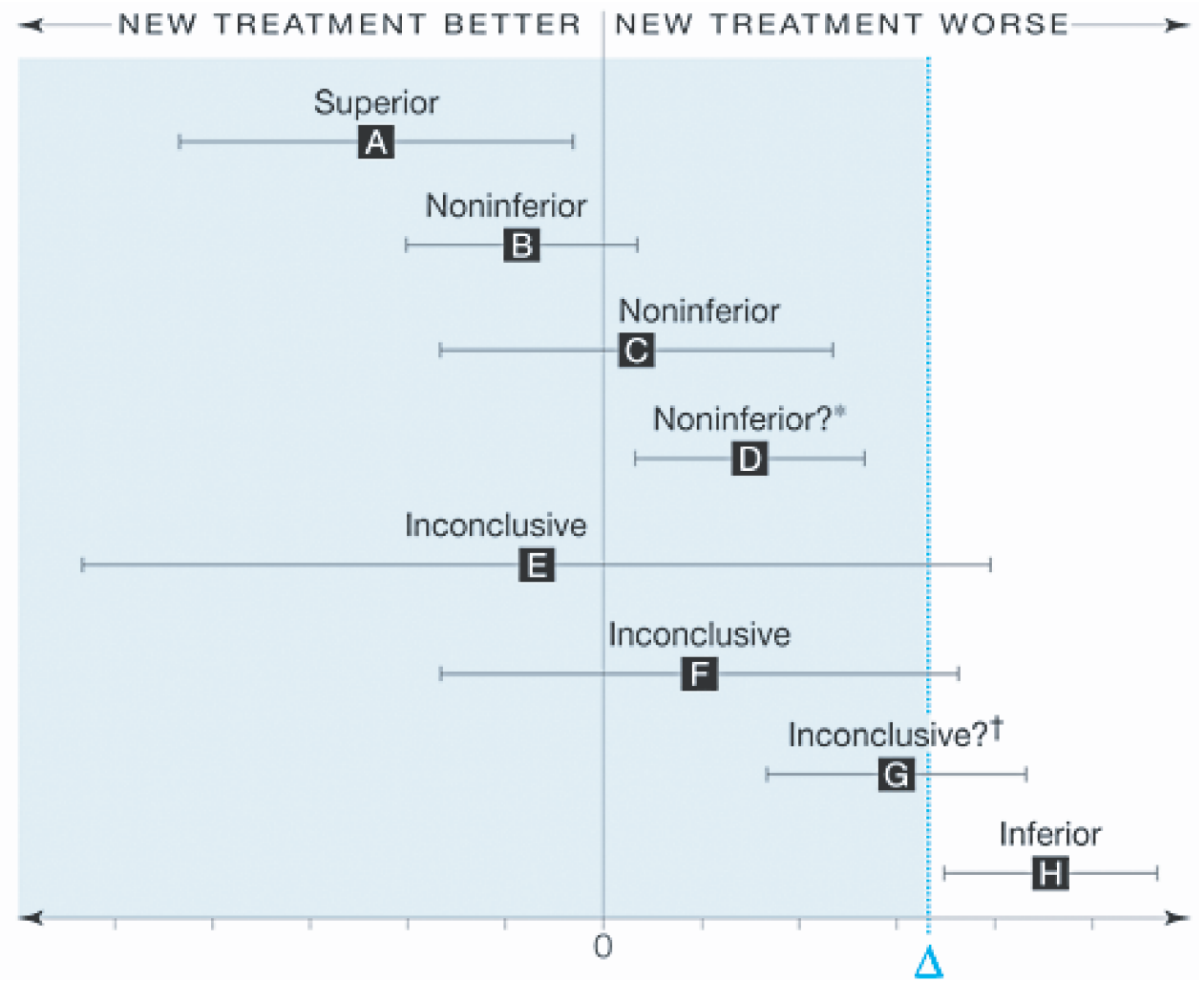

Figure 5 Interpreting non-inferiority and equivalence trials. ${ }^{20}$ Error bars indicate 2 -sided $95 \%$ confidence intervals $(\mathrm{Cl})$. Tinted area indicates zone of inferiority. A, If the $\mathrm{Cl}$ lies wholly to the left of zero, the new treatment is superior. B and C, If the $\mathrm{Cl}$ lies to the left of and includes zero, the new treatment is noninferior but not shown to be superior. D, If the $\mathrm{Cl}$ lies wholly to the left of and wholly to the right of zero, the new treatment is noninferior in the sense already defined, but it is also inferior in the sense that a null treatment difference is excluded. This puzzling case is rare, since it requires a very large sample size. It can also result from having too wide a noninferiority margin. $\mathrm{E}$ and $\mathrm{F}$. If the $\mathrm{Cl}$ includes and zero, the difference is nonsignificant but the result for noninferiority is inconclusive. $\mathrm{G}$, If the $\mathrm{Cl}$ includes and is wholly to the right of zero, the difference is statistically significant but the result is inconclusive for possible inferiority of magnitude or worse. $\mathrm{H}$, If the $\mathrm{Cl}$ is wholly above, the new treatment is inferior. Reproduced with permission from Piaggio G, Elbourne DR,Altman DG, Pocock SJ, Evans SJ. Reporting of noninferiority and equivalence randomized trials: an extension of the CONSORT statement. JAMA. 2006; 295: I I52-1 160. ${ }^{20}$ Copyright @ 2006 American Medical Association, All rights reserved. 
hyperemia is of concern to clinicians for two main reasons: hyperemia may compromise the outcome of filtration surgery, and it may represent a cosmetic problem to the patient thereby likely to lead to poor treatment adherence. ${ }^{46}$ The extent that hyperemia contributes to poor adherence and the effect of administration of the prostaglandin derivatives on outcome filtration surgery remains to be determined. However, a recent evaluation examining reasons for patient discontinuation and poor adherence of PGA therapy found that hyperemia impacted almost two-thirds of patients with adverse events. ${ }^{47}$ Given that these evaluations come from head-to-head trials, they provide strong inferences regarding clinical efficacy and public health implications. Conjunctival hyperemia appears to occur via a secondary mechanism, unrelated to the increased uveoscleral outflow mechanism induced by PGA therapy. While this effect may lessen over time, ${ }^{48}$ it may represent a cosmetic concern to the patient, that may lead to poor treatment adherence and thus poor outcomes. ${ }^{46}$ In general, PGAs have few systemic adverse events and local ones are mainly transitory or reversible, supporting their use as first line therapy. Beta-blockers on the other side have a greater risk of systemic adverse events, but fewer local and cosmetic side-effects. ${ }^{46,48}$ Of note, adherence to treatment may depend on side-effects, but also on the frequency of instillation of the drops and the presence of preservative agents, the latter inducing a local reaction, that can have a negative effect on surgery, making the rate of success lower. ${ }^{49}$

\section{Conclusions}

PGAs remain powerful drugs in first-line therapy of open angle glaucoma and ocular hypertension. Clinicians and ophthalmologists choosing therapies should take into account the costs associated with individual drugs, their efficacy, the adverse events associated with them, and adherence to treatment.

\section{Author contributions}

OE, EM, CLW, BR, SK conceived the study. EM, CWL, BR, SK, OE designed the study. EM, CWL, BR, SK, OE abstracted and analyzed the data. EM, CWL, BR, SK, OE, JN, PL, DM interpreted the data. EM, CLW, BR, SK, OE, JN, PL, DM wrote the paper. EM, CLW, BR, SK, OE, JN, PL, DM approved the final manuscript.

\section{Disclosures}

Funding/support was provided by Pfizer Ltd.
EM has received funding support from Pfizer Ltd during the last 5 years. CWL and SK have been employed by Pfizer Ltd during the last 5 years. Pfizer Ltd is the maker of latanoprost.

\section{References}

1. Coleman AL. Glaucoma. Lancet. 1999;354:1803-1810.

2. Maier PC, Funk J, Schwarzer G, Antes G, Falck-Ytter YT. Treatment of ocular hypertension and open angle glaucoma: meta-analysis of randomised controlled trials. BMJ. 2005;331:134.

3. Weigert G, Findl O, Luksch A, et al. Effects of moderate changes in intraocular pressure on ocular hemodynamics in patients with primary open-angle glaucoma and healthy controls. Ophthalmology. 2005;112:1337-1342.

4. Gordon MO, Beiser JA, Brandt JD, et al. The Ocular Hypertension Treatment Study: baseline factors that predict the onset of primary open-angle glaucoma. Arch Ophthalmol. 2002;120:714-720; discussion 829-730.

5. Kass MA, Heuer DK, Higginbotham EJ, et al. The Ocular Hypertension Treatment Study: a randomized trial determines that topical ocular hypotensive medication delays or prevents the onset of primary openangle glaucoma. Arch Ophthalmol. 2002;120:701-713; discussion 829-730.

6. Vass C, Hirn C, Sycha T, Findl O, Bauer P, Schmetterer L. Medical interventions for primary open angle glaucoma and ocular hypertension. Cochrane Database Syst Rev. 2007:CD003167.

7. Hodge WG, Lachaine J, Steffensen I, et al. The efficacy and harm of prostaglandin analogues for IOP reduction in glaucoma patients compared to dorzolamide and brimonidine: a systematic review. $\mathrm{Br} J$ Ophthalmol. 2008;92:7-12.

8. van der Valk R, Webers CA, Schouten JS, Zeegers MP, Hendrikse F, Prins MH: Intraocular pressure-lowering effects of all commonly used glaucoma drugs: a meta-analysis of randomized clinical trials. Ophthalmology. 2005;112:1177-1185.

9. van der Valk R, Schouten JS, Webers CA, et al. The impact of a nationwide introduction of new drugs and a treatment protocol for glaucoma on the number of glaucoma surgeries. J Glaucoma. 2005;14:239-242.

10. Burr J, Azuara-Blanco A, Avenell A. Medical versus surgical interventions for open angle glaucoma. Cochrane Database Syst Rev. 2005: CD004399.

11. Li N, Chen XM, Zhou Y, Wei ML, Yao X. Travoprost compared with other prostaglandin analogues or timolol in patients with open-angle glaucoma or ocular hypertension: meta-analysis of randomized controlled trials. Clin Experiment Ophthalmol. 2006;34:755-764.

12. Denis P, Lafuma A, Khoshnood B, Mimaud V, Berdeaux G. A metaanalysis of topical prostaglandin analogues intra-ocular pressure lowering in glaucoma therapy. Curr Med Res Opin. 2007;23:601-608.

13. Fung AT, Reid SE, Jones MP, Healey PR, McCluskey PJ, Craig JC. Meta-analysis of randomised controlled trials comparing latanoprost with brimonidine in the treatment of open-angle glaucoma, ocular hypertension or normal-tension glaucoma. Br J Ophthalmol. 2007;91:62-68.

14. Cheng JW, Wei RL. Meta-analysis of 13 randomized controlled trials comparing bimatoprost with latanoprost in patients with elevated intraocular pressure. Clin Ther. 2008;30:622-632.

15. American Academy of Ophthalmology Preferred Practice Pattern: Primary open-angle glaucoma (2005) - http://one.aao. org/CE/PracticeGuidelines/PPP.aspx?sid=ca9ec1b5-2567-4e8596f6-b6540e5ac5a1. Accessed July 6, 2009.

16. Schulz KF, Chalmers I, Hayes RJ, Altman DG. Empirical evidence of bias. Dimensions of methodological quality associated with estimates of treatment effects in controlled trials. JAMA. 1995;273:408-412.

17. Devereaux PJ, Manns BJ, Ghali WA, et al. Physician interpretations and textbook definitions of blinding terminology in randomized controlled trials. JAMA. 2001;285:2000-2003. 
18. McAlister FA, Laupacis A, Wells GA, Sackett DL. Users' Guides to the Medical Literature: XIX. Applying clinical trial results B. Guidelines for determining whether a drug is exerting (more than) a class effect. JAMA. 1999;282:1371-1377.

19. Le Henanff A, Giraudeau B, Baron G, Ravaud P. Quality of reporting of noninferiority and equivalence randomized trials. JAMA. 2006;295:1147-1151

20. Piaggio G, Elbourne DR, Altman DG, Pocock SJ, Evans SJ. Reporting of noninferiority and equivalence randomized trials: an extension of the CONSORT statement. JAMA. 2006;295:1152-1160.

21. Meade MO, Guyatt GH, Cook RJ, et al. Agreement between alternative classifications of acute respiratory distress syndrome. Am J Respir Crit Care Med. 2001;163:490-493.

22. DerSimonian R, Laird N. Meta-analysis in clinical trials. Control Clin Trials. 1986;7:177-188.

23. Sheehe PR. Combination of log relative risk in retrospective studies of disease. Am J Public Health Nations Health. 1966;56:1745-1750.

24. Higgins JP, Thompson SG. Quantifying heterogeneity in a meta-analysis. Stat Med. 2002;21:1539-1558.

25. Whitcup SM, Cantor LB, VanDenburgh AM, Chen K. A randomised, double masked, multicentre clinical trial comparing bimatoprost and timolol for the treatment of glaucoma and ocular hypertension. $\mathrm{Br} J$ Ophthalmol. 2003;87:57-62.

26. Cantor LB, Hoop J, Morgan L, Wudunn D, Catoira Y. Intraocular pressure-lowering efficacy of bimatoprost $0.03 \%$ and travoprost $0.004 \%$ in patients with glaucoma or ocular hypertension. $\mathrm{Br} J$ Ophthalmol. 2006;90:1370-1373.

27. Cantor LB, WuDunn D, Cortes A, Hoop J, Knotts S. Ocular hypotensive efficacy of bimatoprost $0.03 \%$ and travoprost $0.004 \%$ in patients with glaucoma or ocular hypertension. Surv Ophthalmol. 2004;49 Suppl 1: S12-S18.

28. Koz OG, Ozsoy A, Yarangumeli A, Kose SK, Kural G. Comparison of the effects of travoprost, latanoprost and bimatoprost on ocular circulation: a 6-month clinical trial. Acta Ophthalmol Scand. 2007;85:838-843.

29. Hepsen IF, Ozkaya E. 24-h IOP control with latanoprost, travoprost, and bimatoprost in subjects with exfoliation syndrome and ocular hypertension. Eye. 2007;21:453-458.

30. Cellini M, Caramazza R, Bonsanto D, Bernabini B, Campos EC. Prostaglandin analogs and blood-aqueous barrier integrity: a flare cell meter study. Ophthalmologica. 2004;218:312-317.

31. Parrish RK, Palmberg P, Sheu WP. A comparison of latanoprost, bimatoprost, and travoprost in patients with elevated intraocular pressure: a 12-week, randomized, masked-evaluator multicenter study. Am J Ophthalmol. 2003;135:688-703.

32. Arcieri ES, Santana A, Rocha FN, Guapo GL, Costa VP. Blood-aqueous barrier changes after the use of prostaglandin analogues in patients with pseudophakia and aphakia: a 6-month randomized trial. Arch Ophthalmol. 2005;123:186-192.

33. Topouzis F, Melamed S, Danesh-Meyer H, et al. A 1-year study to compare the efficacy and safety of once-daily travoprost $0.004 \% /$ timolol $0.5 \%$ to once-daily latanoprost $0.005 \% /$ timolol $0.5 \%$ in patients with open-angle glaucoma or ocular hypertension. Eur J Ophthalmol. 2007; 17:183-190.
34. Cardascia N, Vetrugno M, Trabucco T, Cantatore F, Sborgia C. Effects of travoprost eye drops on intraocular pressure and pulsatile ocular blood flow: a 180-day, randomized, double-masked comparison with latanoprost eye drops in patients with open-angle glaucoma. Current Therapeutic Research. 2003;64:389-400.

35. Parmaksiz S, Yuksel N, Karabas VL, Ozkan B, Demirci G, Caglar Y. A comparison of travoprost, latanoprost, and the fixed combination of dorzolamide and timolol in patients with pseudoexfoliation glaucoma. Eur J Ophthalmol. 2006;16:73-80.

36. Netland PA, Landry T, Sullivan EK, et al. Travoprost compared with latanoprost and timolol in patients with open-angle glaucoma or ocular hypertension. Am J Ophthalmol. 2001;132:472-484.

37. Noecker RJ, Earl ML, Mundorf TK, Silverstein SM, Phillips MP. Comparing bimatoprost and travoprost in black Americans. Curr Med Res Opin. 2006;22:2175-2180.

38. Noecker RJ, Earl ML, Mundorf T, Peace J, Williams RD. Bimatoprost $0.03 \%$ versus travoprost $0.004 \%$ in black Americans with glaucoma or ocular hypertension. Adv Ther. 2003;20:121-128.

39. Dirks MS, Noecker RJ, Earl M, Roh S, Silverstein SM, Williams RD. A 3-month clinical trial comparing the IOP-lowering efficacy of bimatoprost and latanoprost in patients with normal-tension glaucoma. Adv Ther. 2006;23:385-394.

40. Gandolfi S, Simmons ST, Sturm R, Chen K, VanDenburgh AM. Three-month comparison of bimatoprost and latanoprost in patients with glaucoma and ocular hypertension. Adv Ther. 2001;18:110-121.

41. Noecker RS, Dirks MS, Choplin NT, Bernstein P, Batoosingh AL, Whitcup SM. A six-month randomized clinical trial comparing the intraocular pressure-lowering efficacy of bimatoprost and latanoprost in patients with ocular hypertension or glaucoma. Am J Ophthalmol. 2003;135:55-63.

42. Mundorf T, Noecker RJ, Earl M: A multicenter, investigator-masked, randomized comparison of the IOP-lowering efficacy of bimatoprost $0.03 \%$ versus travoprost $0.004 \%$ in African Americans with glaucoma or ocular hypertension. Invest Ophthalmol Vis Sci. 2004;45:E-Abstract 4502.

43. Eyawo O, Lee CW, Rachlis B, Mills EJ. Reporting of noninferiority and equivalence randomized trials for major prostaglandins: A systematic survey of the ophthalmology literature. Trials. 2008;9:69.

44. Sowka JW, Gurwood AS, Kabat AG: Handbook of Ocular Disease Management: Review of Optometry. 2002. http://www.revoptom. com/HANDBOOK/hbhome.htm. Accessed July 17, 2009.

45. Owen CG, Carey IM, de Wilde S, Whincup PH, Wormald R, Cook DG. Persistency with medical treatment for glaucoma and ocular hypertension in the United Kingdom: 1994-2005. Eye. 2008. [Epub ahead of print].

46. Feldman RM. Conjunctival hyperemia and the use of topical prostaglandins in glaucoma and ocular hypertension. J Ocul Pharmacol Ther. 2003; 19:23-35.

47. Friedman DS, Hahn SR, Gelb L, et al. Doctor-patient communication, health-related beliefs, and adherence in glaucoma results from the Glaucoma Adherence and Persistency Study. Ophthalmology. 2008;115:1320-1327.

48. Hollo G: The side effects of the prostaglandin analogues. Expert Opin Drug Saf. 2007;6:45-52.

49. Baudouin C, Garcher C, Haouat N, Bron A, Gastaud P. Expression of inflammatory membrane markers by conjunctival cells in chronically treated patients with glaucoma. Ophthalmology. 1994;101:454-460.
Clinical Ophthalmology

\section{Publish your work in this journal}

Clinical Ophthalmology is an international, peer-reviewed journal covering all subspecialties within ophthalmology. Key topics include: Optometry; Visual science; Pharmacology and drug therapy in eye diseases; Basic Sciences; Primary and Secondary eye care; Patient Safety and Quality of Care Improvements. This journal is indexed on Submit your manuscript here: http://www.dovepress.com/clinical-ophthalmology-journal
Dovepress

PubMed Central and CAS, and is the official journal of The Society of Clinical Ophthalmology (SCO). The manuscript management system is completely online and includes a very quick and fair peer-review system, which is all easy to use. Visit http://www.dovepress.com/ testimonials.php to read real quotes from published authors. 